\title{
REQUISITOS PARA A GESTÃO DO CONHECIMENTO NA ADMINISTRAÇÃO PÚBLICA UNIVERSITÁRIA EM SEU PARADIGMA TECNOLÓGICO ${ }^{1}$ REQUIREMENTS FOR THE MANAGEMENT OF KNOWLEDGE IN PUBLIC ADMINISTRATION UNIVERSITY IN HIS TECHNOLOGIC PARADIGM
}

\author{
Cristiane Marques de Mello ${ }^{2}$ \\ Álvaro José Periotto ${ }^{3}$ \\ João Otávio Montanha Endrici ${ }^{4}$
}

RESUMO: Cada vez mais as organizações 'descobrem' a necessidade de trabalhar informações qualificadas para gerar novos conhecimentos, novos valores e evoluir. Para verificar como as instituições públicas de ensino superior assumem posições frente a tais aspectos diante da dinâmica dos recursos tecnológicos, adotou-se como objetivo de pesquisa posicionar a Gestão do Conhecimento frente ao planejamento e uso da Tecnologia da Informação na gestão das instituições públicas universitárias. A pesquisa caracteriza-se como exploratória, o estudo é de natureza quantitativa e o recorte da pesquisa é transversal. Como unidades de pesquisa foram escolhidas três instituições públicas de ensino superior, duas estaduais e uma delas federal, localizadas no Estado do Paraná. Entre os respondentes estão chefes de departamentos, diretores e coordenadores de cursos vinculados a tais instituições. A investigação foi realizada por meio de um questionário estruturado, concluindo-se pela necessidade emergente de desenvolver-se competências e habilidades de gestão com rompimento de uma visão ainda estreita e imediatista quanto aos sistemas de informação.

PALAVRAS-CHAVE: Gestão do Conhecimento; Paradigma Tecnológico, Tecnologia da Informação; Sistemas de Informação; Administração Pública.

ABSTRACT: Increasingly organizations 'discover' the need to work to generate information which new knowledge, new values and to evolve. To see how the public institutions of higher education take positions on such issues before the dynamics of technological resources, we adopted as a goal to search the Knowledge Management and the planning of the use of Information Technology in the management of Public Universities. The research is characterized as exploratory, the study is quantitative in nature with a cross section cut. As units of study were chosen three public institutions of higher education located in the Paraná State. Among the respondents are heads of departments, directors and coordinators of courses related to such institutions. The research was conducted through a structured questionnaire, concluding there is a emerging need to develop competencies and skills of management with a vision of breaking even close and immediate about the information systems.

KEYWORDS: Knowledge Management; Technologic Paradigm, Information Technology, Information Systems, Public Administration.

\footnotetext{
${ }^{1}$ Artigo Recebido em 24.06.2009. Revisado por pares em 26.07.2011. Recomendado em 02.08.2011 por Leomar dos Santos Editor. Publicado em 15.09.2011.

Organização Responsável pelo periódico: Universidade regional de Blumenau - FURB - www.furb.br/rn
}

${ }^{2}$ Universidade Positivo - POSITIVO - mellcris@ gmail.com

${ }^{3}$ Universidade Estadual de Maringá - UEM - ajperiotto@uem.br

${ }^{4}$ Faculdades Maringá - FM - jendrici@hotmail.com 


\section{INTRODUÇÃO}

Duas criações foram de extrema relevância à humanidade: a escrita e a imprensa. A criação da escrita conservou os registros do conhecimento, possibilitando a expansão cultural; e a criação da imprensa proporcionou o acesso a esse conhecimento e sua proliferação (CARVALHO; KANISKI, 2000). A Internet foi a forma encontrada para disseminar com maior intensidade e agilidade a escrita e a divulgação das informações publicadas pela imprensa. A Internet é caracterizada como uma rede de redes, de acesso público, um sistema global de rede de computador, com abrangência mundial (TURBAN, RAINER; POTTER, 2005). Foi a partir dos anos 90 que a utilização da Internet foi intensificada e difundida por milhões de usuários. De acordo com Duffy (2001) o que favoreceu a utilização da Internet com maior freqüência foi a queda de preços nas tecnologias de digitalização; criação da banda larga; e maior alcance da Internet pela população.

A informática é capaz de realizar muito além do que simplesmente capturar e armazenar dados. Tanto o desenvolvimento tecnológico em inteligência artificial como de outras técnicas de processamento de informação, conduzem à verificação e generalização de dados armazenados, e também à descoberta de novos conhecimentos (ERIC TSUI, 2005).

No ambiente globalizado no qual as organizações estão inseridas, as informações e a geração de novos conhecimentos torna-se um requisito de sobrevivência para as mesmas. As transformações no cenário tecnológico, bem como o reconhecimento da necessidade de acompanhar a sua evolução, faz com que as organizações, privadas e públicas, busquem estar "conectadas" com o mundo virtual. As mudanças no ambiente tecnológico contribuem para a criação de novas formas de administração organizacional. A GC a Gestão do Conhecimento (GC) ou Knowledge Management (KM), um modo de gestão muito discutido, é uma forma de administrar através da ênfase no compartilhamento do conhecimento e na criação de novos conhecimentos.

Não se pode negar que a Tecnologia da Informação (TI) está estreitamente ligada à GC. A TI oferece muitas ferramentas para auxiliar às empresas na GC e, segundo Duffy (2001), outras novas e revolucionárias ideias. O conceito original foi desenvolvido em um ambiente empresarial, entretanto, os vendedores de tecnologia reconheceram a oportunidade rapidamente e projetaram sistemas para apoiar a ideia.

A presente pesquisa tem seu foco voltado para os Sistemas de Informação atualmente utilizados pelas organizações públicas universitárias. Um sistema de informação, nas palavras de Laudon e Laudon (1999) é composto pela tecnologia, organizações e por pessoas com habilidades diferentes. O levantamento dos dados considera a Gestão de Informação no patamar da atual "Sociedade da Informação", ou seja, sob as contribuições da tecnologia digital (Informática e Telecomunicações) e da Administração para estabelecer uma estratégia que se apóia nas "soluções" integradas destas áreas para atender às atuais demandas de informações. Com o intuito de verificar como aquelas mudanças contribuem e/ou afetam o uso da tecnologia nas instituições públicas de ensino superior, foi proposto para a presente pesquisa como principal objetivo: posicionar a Gestão do Conhecimento (GC) frente ao 
planejamento e o uso da Tecnologia da Informação (TI) na gestão das instituições públicas universitárias.

Primeiramente, serão explanados os aspectos e elementos que constituem a GC, depois a Universidade e o Sistema de Informação. Posteriormente, são descritas a metodologia utilizada para a pesquisa, a análise e interpretação dos resultados, e finalmente, as conclusões.

\section{ASPECTOS E ELEMENTOS DA GESTÃO DO CONHECIMENTO}

O tema Gestão do Conhecimento tem se destacado nos últimos dez anos especialmente na área de gestão empresarial, apesar ter sido tratado em áreas diferentes: administração, engenharia de produção, psicologia, ciência da computação, educação (PERROTTI; VASCONCELLOS, 2005).

Um dos elementos a ser abordado aqui é o dado que por si só não expressa algo significativo, nem expressa relevante valor. Entretanto, os dados são elementos que formam as informações consideradas importantes ao processo da geração de conhecimento. O conhecimento pode também ser definido como a informação processada pelos indivíduos. Em um contexto mais amplo, a informação, conforme aponta Alves e Barbosa (2010) pode ocupar posições como: parte do processo; principal produto; central aos processos produtivos econômico e social; e até como uma ferramenta de emancipação humana e social. Considerando os elementos conceituais, Angeloni (2003) define os dados como elementos brutos, sem significado algum, e que constituem a matéria-prima da informação, visão também compartilhada por Laudon e Laudon (1999). Davenport e Prusak (1998) consideram os dados como um aglomerado de diferentes fatos e objetivos, referentes a eventos, descritos no âmbito organizacional, como registros estruturados de transações.

Para exemplificar a inter-relação entre dados, informação e conhecimento utilizamos a figura abaixo, elaborada por Turban, Rainer e Potter (2005).

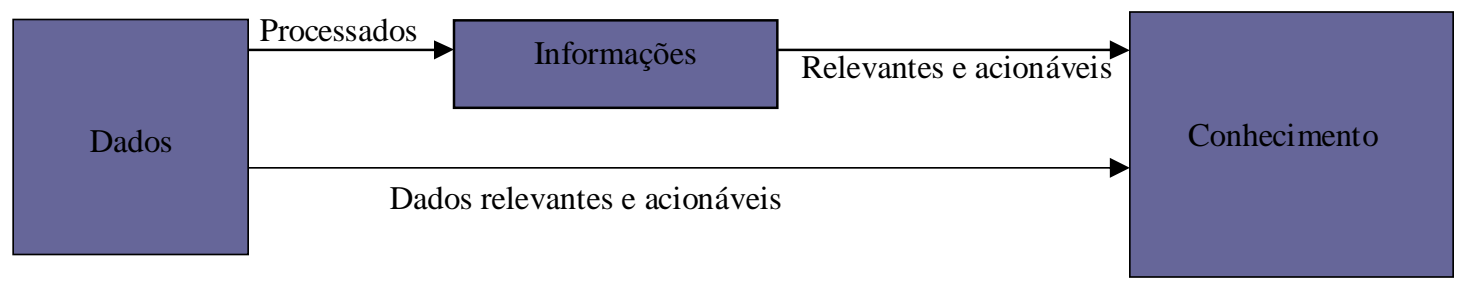

Figura 1 - Dados, Informações e Conhecimento

Fonte: Turban, Rainer e Potter (2005, p. 101)

Os dados são elementos fundamentais para a informação ser gerada. A informação é como uma mensagem escrita, falada ou visualizada, possui um emissor e um receptor, cujo objetivo está em exercer influência no julgamento e comportamento daquele que a recebe. São dados que fazem a diferença e com significados (DAVENPORT E PRUSAK, 1998). Ressaltamos que na Tecnologia da Informação (TI), o conhecimento e a informação podem ser comumente usados como sinônimos, porém Beal (2004) alerta para o fato de que um 
conglomerado de informações não, necessariamente, é caracterizado como conhecimento gerado.

O conhecimento é definido por Sveiby (1998, p. 44) como "uma capacidade de agir". $\mathrm{O}$ autor ainda menciona que o conhecimento pode ser transmitido pela informação por meio de apresentações orais e também de um para o outro, através da prática. Em relação ao conhecimento, Davenport e Prusak (1998) preferem dar uma definição funcional que possa expressar o que querem dizer quando mencionam o conhecimento nas organizações. Então definem conhecimento como:

"Conhecimento é uma mistura fluida de experiência condensada, valores, informação contextual e insight experimentado, a qual proporciona uma estrutura para a avaliação e incorporação de novas experiências e informações. Ele tem origem e é aplicado na mente dos conhecedores. Nas organizações, ele costuma estar embutido não só em documentos ou repositórios, mas também em rotinas, processos, práticas e normas organizacionais" (DAVENPORT; PRUSAK, 1998, p. 6).

O valor agregado à informação depende dos conhecimentos anteriores desses indivíduos, o conhecimento está estritamente relacionado com a percepção dos mesmos. (ANGELONI, 2003). Existem quatro características do conhecimento, mencionadas por Sveiby (1998): (1) o conhecimento é tácito, (2) é orientado para a ação, (3) é sustentado por regras, e (4) está em constante mutação.

A Gestão do Conhecimento (GC) envolve a interação entre indivíduos e trocas de conhecimentos; e a determinação do que a empresa sabe ou deveria saber para atingir seus objetivos estratégicos (VASCONCELOS, 2001). A geração do novo conhecimento é o resultado da interação dinâmica entre funcionários de alto nível, daqueles de nível médio e dos considerados seniores (NONAKA; TAKEUCHI, 1997). Duffy (2001) comenta que nesta era, é preciso encorajar os gerentes inteligentes e apoiar o uso ótimo de conhecimento para estimular inovação, sustentar aprendizagem, melhorar desempenho, e aumentar valor de acionista. De acordo com Sveiby (1998), as pessoas essenciais na participação do conhecimento na organização são o profissional (especialistas são mais qualificados), o gerente, o pessoal de suporte e o líder.

A figura 2 exibe uma representação das duas dimensões da criação do conhecimento, segundo os autores supra mencionados. 


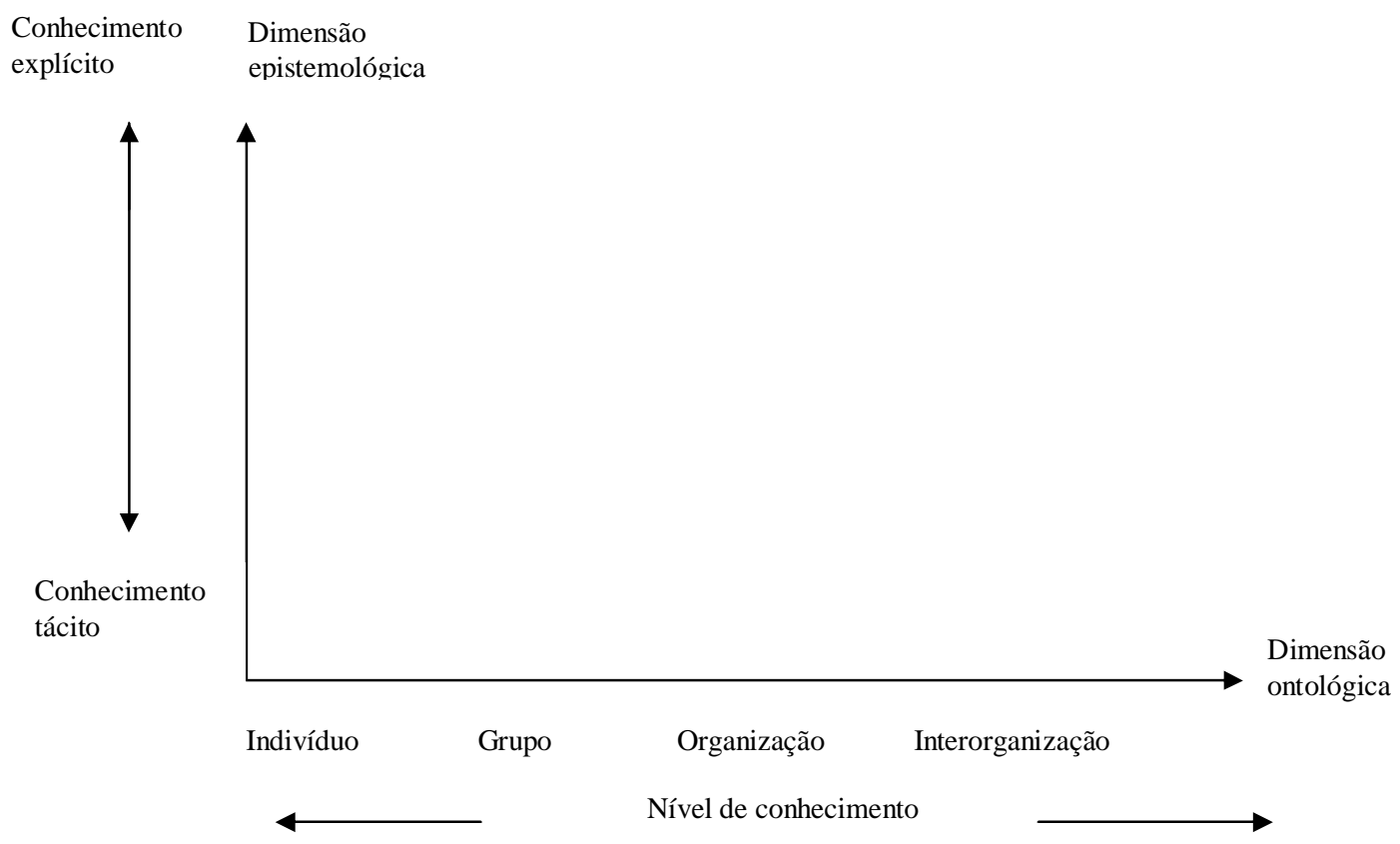

Figura 2 - Representação das duas dimensões da criação do conhecimento

Fonte: Nonaka e Takeuchi (1997 p. 62)

Na criação do conhecimento há duas dimensões, a ontológica e a epistemológica. Na dimensão ontológica o conhecimento é criado pelos indivíduos que alargam a rede de conhecimentos da organização por meio da interação com outros. A organização não está apta a gerar conhecimento sem os indivíduos. Na segunda dimensão acontece a transformação do conhecimento tácito em conhecimento explícito. O conhecimento tácito é mais enfatizado pelos japoneses, enquanto que o conhecimento explícito é mencionado com maior ênfase pelos ocidentais. O conhecimento contém tanto elementos de definição japonesa quanto ocidentais, desse modo as duas perspectivas são complementares (NONAKA; TAKEUCHI, 1997).

O quadro 1 estabelece um comparativo entre o conhecimento tácito e o conhecimento explícito.

\begin{tabular}{|l|l|}
\hline $\begin{array}{l}\text { Conhecimento tácito } \\
\text { (subjetivo) }\end{array}$ & $\begin{array}{l}\text { Conhecimento explícito } \\
\text { (objetivo) }\end{array}$ \\
\hline $\begin{array}{l}\text { Conhecimento da experiência } \\
\text { (corpo) }\end{array}$ & $\begin{array}{l}\text { Conhecimento da racionalidade } \\
\text { (mente) }\end{array}$ \\
\hline $\begin{array}{l}\text { Conhecimento simultâneo } \\
\text { (aqui e agora) }\end{array}$ & $\begin{array}{l}\text { Conhecimento seqüencial } \\
\text { (lá e então) }\end{array}$ \\
\hline $\begin{array}{l}\text { Conhecimento análogo } \\
\text { (prática) }\end{array}$ & $\begin{array}{l}\text { Conhecimento digital } \\
\text { (teoria) }\end{array}$ \\
\hline
\end{tabular}

Quadro 1 - Comparativo entre o conhecimento tácito e explícito

Fonte: Adaptado de Nonaka e Takeuchi (1997) 
Em resumo, o conhecimento tácito é o conhecimento difícil de ser transmitido, documentado ou ensinado a outros (BEAL, 2004), e se constitui por elementos técnicos, já o conhecimento explícito pode ser transmitido em linguagem formal (NONAKA; TAKEUCHI, 1997), por meio de documentos, roteiros e/ou treinamentos (BEAL, 2004).

A patir dessas considerações preliminares pode-se inferir que gerenciar conhecimento não é tão simples. Alves e Barbosa (2010) consideram a gestão do conhecimento como um processo complexo e multifacetado, e alertam que esse tipo de gestão precisa agregar em seu escopo, fatores motivacionais e cognitivos vinculados à geração e compartilhamento do conhecimento.

A fim de aprofundarmos um pouco mais o assunto em direção aos objetivos propostos inicialmente, discorremos na seção seguinte sobre o sistema e a gestão da informação no ambiente universitário.

\subsection{A Universidade e os Sistemas de Informação}

A tecnologia, os sistemas de informações, a geração de novos conhecimentos são ferramentas importantes tanto para as organizações privadas quanto para as públicas. Nessa seção procurou-se mencionar alguns aspectos relevantes do ambiente universitário e sua relação com o sistema de informação, considerados pertinentes aos objetivos inicialmente propostos.

O ambiente universitário é um ambiente extremamente formalizado e que sofre interferência direta nas mudanças das leis relacionadas à educação do ensino superior. A educação superior é definida por Colossi, Consentino e Queiroz (2001), como uma instituição social, estável e duradoura, concebida a partir de normas e valores da sociedade. O conceito de universidade é expresso por significado jurídico, social, institucionalizado, por meio de leis, decretos, estatutos, e estrutura física. "Expressa-se dinamicamente em torno de fenômenos culturais e sociais cerceados pelas forças da tradição e do futuro" (BARROS; LEHFELD, 2000, p. 9).

Fazendo menção a Meister (2000), Marra e Melo (2003) lembram que o aumento da demanda pelo ensino superior, a mudança estrutural dos empregos, a era da informação e a interdependência global, são aspectos que representam novos desafios às universidades e a seus gerentes. As transformações podem ocorrer no âmbito mais amplo. Conforme Colossi, Consentino e Queiroz (2001), as mudanças organizacionais atingem subsistemas relacionados com a estrutura, cultura, tecnologia, ambiente e pessoas, embora a mudança na estrutura é mais fácil do que na cultura, que requer alterações em valores organizacionais. E o processo da globalização mundial coloca uma série de desafios para a universidade brasileira (BARROS; LEHFELD, 2000).

O papel da gestão da informação na Administração Pública transcende a finalidade de melhorar o desempenho organizacional, tarefa que exige exame cuidadoso das soluções induzidas pelo vasto ferramental de TI. Ele vai além, portanto, para buscar condições para que de fato se estabeleça um sistema de gestão organizacional que valorize as dimensões organizacionais existentes e o uso da TI na disseminação da informação e do conhecimento organizacional (BATISTA, 2004). 
Para Marra e Melo (2003) são os dirigentes universitários, como os reitores, próreitores, diretores de unidades, chefes de departamento, coordenadores de curso, que viabilizam o alcance dos objetivos da instituição através de práticas gerenciais, decisões e ações. Além de combater o patrimonialismo e o clientelismo vigentes durante tantos anos, a modernização da administração pública deve objetivar: o aperfeiçoamento da qualidade da sua prestação de serviços à sociedade; aprimorar o controle social; fazer mais ao menor custo possível, aumentando substancialmente a sua eficiência, pois não há recursos infinitos disponíveis para o alcance de todas as demandas sociais, sendo imperioso, portanto, eliminar o desperdício; combater vigorosamente a corrupção com um controle interno, externo e social mais efetivo; e ainda, valorizar o servidor público (SPINELLI; 2003, TERRA et al.;2005).

Os sistemas de informação integrados, conforme Mussi e Angeloni (2004), têm tido destaque nos últimos anos considerado como relevante recurso para a realização e gestão integrada das atividades das organizações. As autoras investigaram o processo de implementação de um sistema de informação integrado baseado em pacote de software em uma instituição de ensino superior do Estado de Santa Catarina. Com o estudo, as pesquisadoras objetivaram verificar de que maneira ocorreu o compartilhamento do conhecimento entre as partes envolvidas e de que modo esse compartilhamento influenciou esse processo. Elas também relacionaram aspectos tanto dificultadores como facilitadores no compartilhamento do conhecimento. Em relação aos meios de compartilhamento de conhecimento foram detectados como fatores facilitadores: compartilhamento do conhecimento explícito e do conhecimento tácito; e a ausência de fatores dificultadores. No que diz respeito à capacidade de absorção observou-se como aspectos facilitadores: a experiência de alguns integrantes da equipe da Universidade em outros projetos de implementação de sistemas integrados; conhecimentos e experiências dos consultores em implantações de sistemas realizadas em outras empresas; e como aspectos dificultadores: a necessidade de maior conhecimento prévio do sistema e da visão por processos de alguns integrantes da equipe da instituição, falta de experiência da consultoria no segmento universitário.

$\mathrm{Na}$ prática, estas discussões acerca do processo de informatização no setor público alavanca o aspecto interno, de atendimento aos serviços que sustentam as atividades da organização pública e o externo, pautado pelo atendimento ao público que, conforme Oliveira et al. (2003), justificam a proliferação de arquiteturas de sistemas de informação, cujo público seja composto não somente pelos funcionários, mas também pelos usuários finais do sistema. A implementação de um sistema de informação amplo e integrado é incorporado por diferentes conhecimentos. Nesse processo é necessário que haja confiança, tanto entre os membros da organização, como também a interação entre os membros organizacionais e os consultores externos do sistema (MUSSI; ANGELONI, 2004).

A Gestão da Informação reúne as contribuições da tecnologia e da administração para estabelecer uma estratégia integrada para se trabalhar, com sistemas de informações, as coerentes mudanças organizacionais. Pode então ser definida, de acordo com Davenport, Marchand e Dickson (2004, p. 185) como sendo "a utilização adequada das ferramentas de informática, comunicação e automação juntamente com as técnicas de organização e gestão alinhadas com a estratégia de negócios com o objetivo de aumentar a competitividade da 
empresa". Estes autores apontam algumas formas de se melhorar a gestão da informação através da compreensão de estilos e limites cognitivos: I) projetar sistemas de informação não apenas para se responder a indagações, mas para se fornecer informação útil que ajudará as pessoas a solucionarem problemas relacionados ao trabalho e a lidarem com exigências específicas de situações problemáticas; II) aumentar a consciência sobre a natureza da busca e do processo humanos da informação; III) educar todos na gestão da qualidade e da quantidade da informação; e IV) desenvolver uma cultura organizacional que valoriza e encoraja o compartilhamento do conhecimento. (DAVENPORT; MARCHAND; DICKSON, 2004, p. 186).

A modernização administrativa relaciona-se fortemente com a Gestão da Informação e da tecnologia afeta. Num primeiro momento, o que realmente se sobressai são os investimentos em equipamentos, mais modernos, mais ágeis, e que deixam claro tanto para o servidor quanto para o cidadão o que isso representa em termos monetários para o setor público.

$\mathrm{Na}$ seção seguinte estão descritos os procedimentos metodológicos utilizados no presente estudo.

\section{METODOLOGIA}

A pesquisa caracteriza-se como exploratória, pois visa a familiarização com o fenômeno ou tema a ser estudado (SELLTIZ, et al. 1975), e permite ao pesquisador aumentar sua experiência em relação a determinado problema de pesquisa (TRIVIÑOS, 1987). O estudo é predominantemente de natureza quantitativa e o recorte da pesquisa é transversal, realizada em 2007.

Como unidades de pesquisa foram escolhidas três instituições públicas de ensino superior, duas estaduais e uma delas federal, localizadas no Estado do Paraná. Entre os respondentes estão chefes de departamentos, diretores e coordenadores de cursos vinculados a tais instituições. A amostra caracteriza-se como não probabilística e intencional. Nas amostras não probabilísticas escolhem-se os indivíduos mediante determinados critérios. A amostra intencional é apresentada como a amostra representativa do universo (RICHARDSON, 1999). No método da amostra não probabilística e intencional, a amostra não é selecionada aleatoriamente (BARROS; LEHFELD, 1990). Desse modo, o critério adotado para seleção dos respondentes foi a sua disponibilidade de tempo para as respostas e a disposição em participar da pesquisa.

As instituições aqui serão identificadas através das letras A, B e C. Na instituição A, seis pessoas responderam ao questionário, sete na instituição $\mathrm{B}$ e nove na instituição $\mathrm{C}$, totalizando vinte e dois respondentes. Apenas seis dos respondentes não são docentes, exercendo somente cargo administrativo. A investigação foi realizada por meio de um questionário estruturado composto por sete questões objetivas. Os dados foram coletados na segunda metade do ano de 2007.

A análise dos dados foi realizada com a utilização de operações estatísticas simples, com a utilização de percentuais, mediante a apresentação de gráficos para melhor visualização 
dos resultados. Após a descrição dos dados foi realizada a interpretação dos dados, buscando sua relação com a fundamentação teórica proposta no presente trabalho.

\section{DESCRIÇÃO E ANÁLISE DOS DADOS}

Nesta seção, serão descritas e analisadas as informações coletadas junto aos respondentes vinculados às instituições universitárias pesquisadas. Com o intuito de elucidar melhor ao leitor, foram elaborados alguns gráficos referentes aos resultados.

O objetivo da primeira questão foi de conhecer o atual estágio da Gestão da Informação nas instituições públicas de ensino superior.

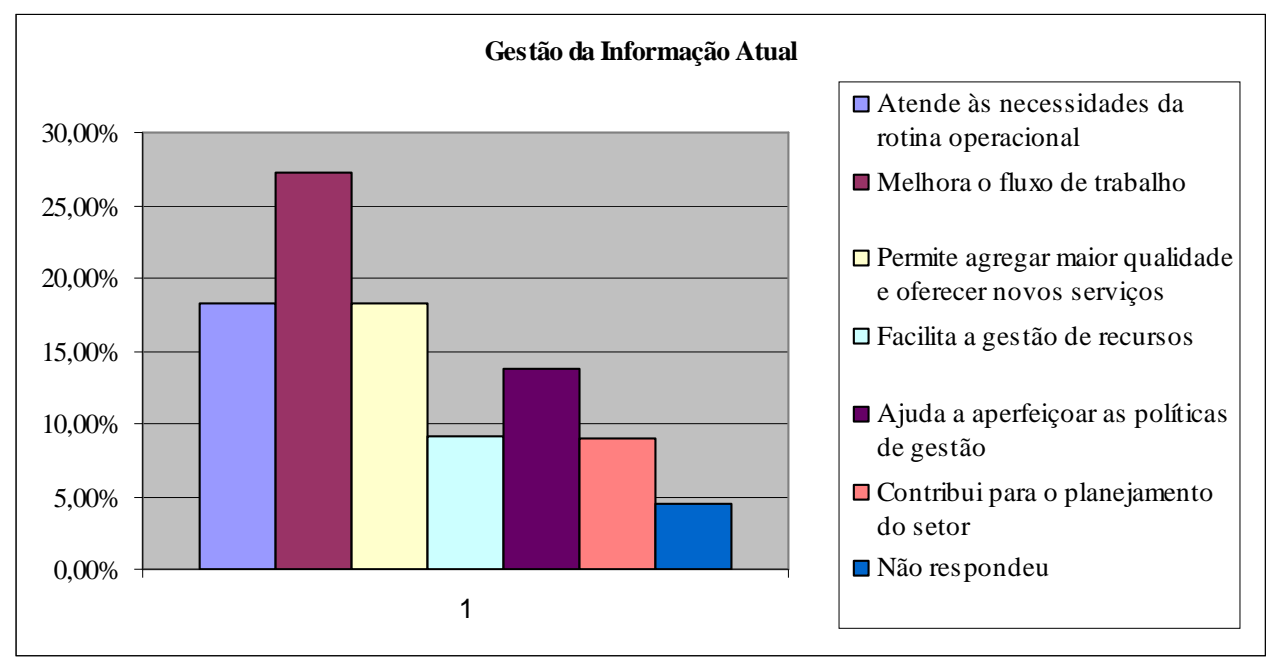

Gráfico 1: Gestão da Informação Atual

Fonte: Dados da pesquisa

Os resultados apontam que na maioria dos casos a Gestão da Informação atual das instituições pesquisadas, servem especialmente para: melhorar o fluxo de trabalho $(27,3 \%)$; atender às necessidades da rotina operacional (18,2\%); e agregar maior qualidade e oferecer novos serviços $(18,2 \%)$. Diante desse quadro, pode-se supor que a gestão da informação pública universitária tem atualmente como principal função operacional otimizar o trabalho rotineiro e proporcionar maior qualidade nos serviços prestados.

Esse resultado, parece condizer com o que foi apontado no trabalho de Alves e Barbosa (2010), no que se refere ao compartilhamento de informação entre indivíduos, como um fator essencial para o êxito organizacional, sugerindo que, provavelmente, a função essencial da gestão do conhecimento seja a de tornar os conhecimentos produtivos e funcionais para aqueles que precisam deles.

No caso da segunda questão, os respondentes deveriam assinalar as alternativas que, no momento da pesquisa, eram correspondentes ao Sistema de Informação no seu setor. As respostas A e C foram as que se sobressaíram, demonstrando que o Sistema de Informação dessas instituições correspondem principalmente aos sistemas de controle que registram e processam transações $(26,6 \%)$; e sistemas que apóiam o planejamento de ações $(26,6 \%)$. A 
maioria (86\%) dos respondentes da instituição B assinalou a alternativa D - não dispomos de Sistemas de Informações, mas apenas de aplicativos e utilitários convencionais (word, antivirus, Internet explorer, etc) - o que significa deficiência no sistema de informação de tal instituição.

Mediante a análise de dados, pressupõe-se que os sistemas de informações, do setor público nas instituições paranaenses de ensino superior servem principalmente como sistemas para planejamento e controle das ações. Entretanto, atenta-se aqui para o fato de que há uma divergência em relação a tal sistema, considerando que existem instituições que não dispõem desse sistema.

A terceira questão estava voltada à infra-estrutura do Sistema de Informação.

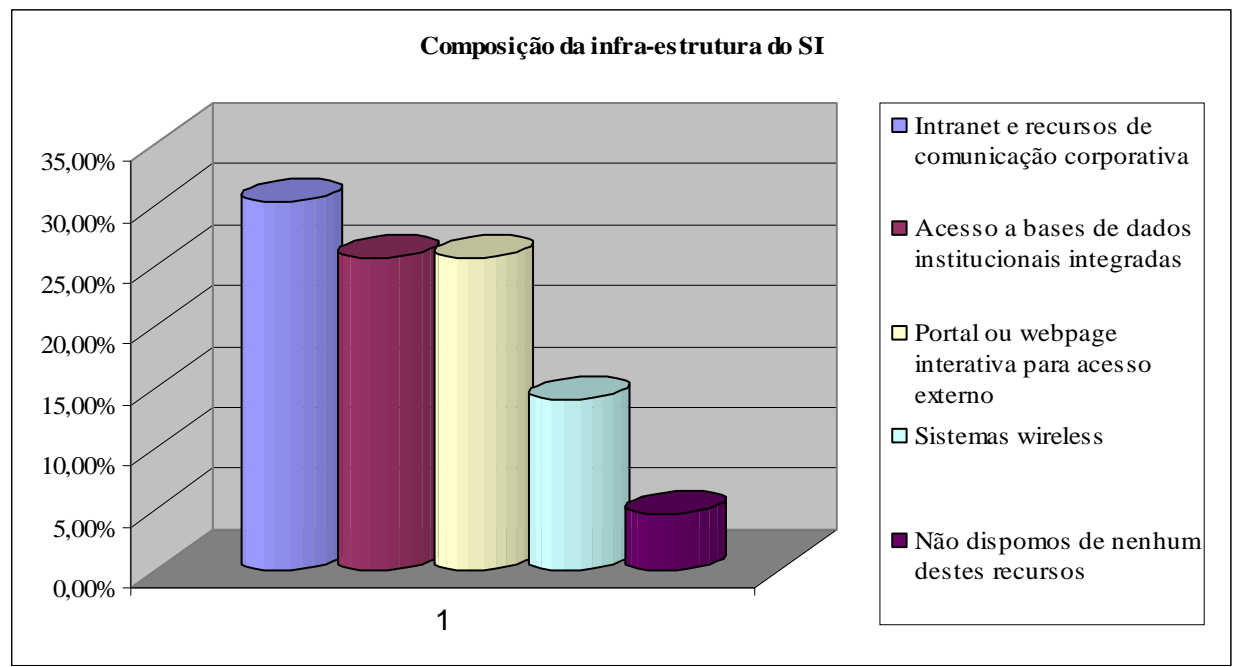

Gráfico 2: Composição da Infra-Estrutura do SI

Fonte: Dados da pesquisa

As respostas obtidas apontaram que a composição da infra-estrutura do SI incluem: a Intranet e recursos de comunicação corporativa (30,2\%); acesso a bases de dados institucionais integradas $(25,6 \%)$; e portal ou webpage interativa para acesso externo $(25,6 \%)$. Ainda $14 \%$ responderam possuir sistemas wireless e 4,6\% disseram não dispor de nenhum destes recursos, o que pode significar desconhecimento por parte de alguns quanto a infraestrutura, posto que foi possível detectar algumas divergências entre os membros da mesma instituição. Todas as instituições pesquisadas possuem Intranet, o que facilita a comunicação organizacional, e, consequentemente possibilita com mais eficiência o acesso à base de dados com aqueles que a integram.

A questão 4 diz respeito à Gestão da Informação, levando em consideração o alinhamento da tecnologia instalada e os processos administrativos, conforme demonstrado no gráfico seguinte. 


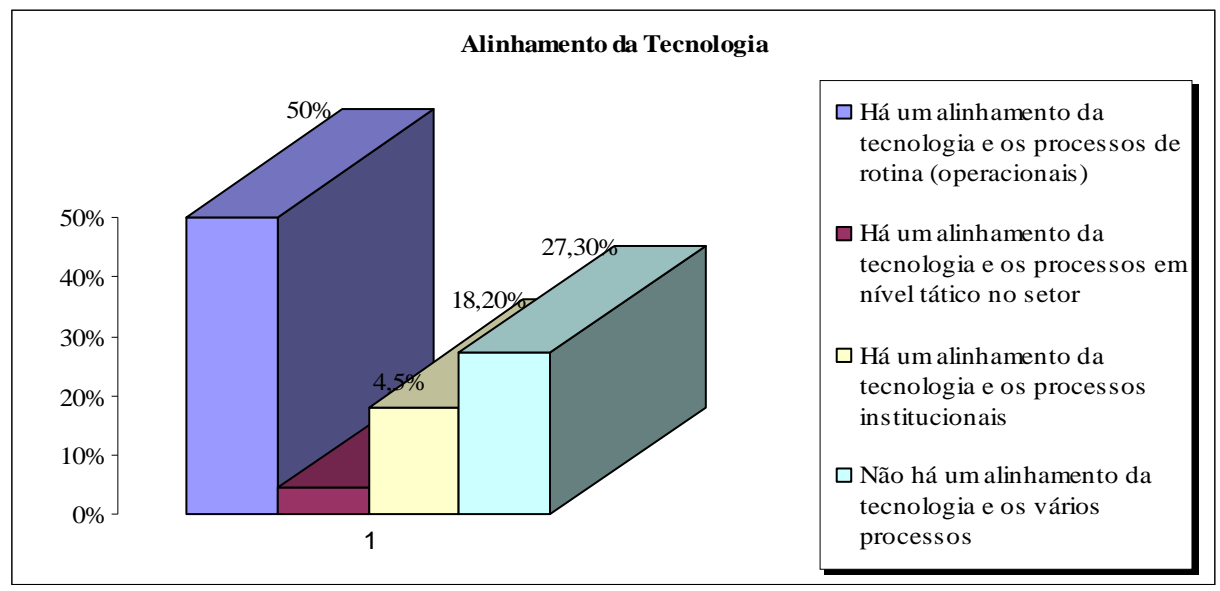

Gráfico 3: Alinhamento da Tecnologia e Processos Inerentes à Administração

Fonte: Dados da pesquisa

Nesse caso, houve uma maior convergência entre as instituições do que nas questões anteriores, posto que, $50 \%$ responderam que há um alinhamento da tecnologia e os processos de rotina (operacionais); e 18,2\% que há um alinhamento da tecnologia e os processos institucionais. Porém, 27,3\% responderam que não existe um alinhamento da tecnologia e os vários processos, tendo como maioria (66\%) dos respondentes a instituição A. Mais de $68 \%$ das respostas afirmam que existe um alinhamento entre a tecnologia institucional, ações rotineiras e os processos institucionais. Contudo, é importante considerar o percentual daqueles que responderam de forma contrária, especialmente porque a maioria desses respondentes pertence à mesma instituição. Isso pressupõe que existe uma disparidade entre as organizações públicas de ensino superior.

Outros estudos sobre alinhamento da tecnologia da informação com os objetivos organizacionais, como a investigação de fatores promotores e inibidores (Luftman; Papp; Brier, 1999; PEREIRA; DORNELAS, 2010), e relação do alinhamento com o planejamento empresarial (REZENDE, 2002), contribuem para a ampliação da compreensão do que foi discutido até o momento.

$\mathrm{Na}$ questão 5, a alternativa a ser marcada era aquela que estava mais condizente com as necessidades de Gestão da Informação (GI). Mais uma vez, aqui houve uma maior convergência das respostas entre as unidades de análise, tendo em vista que a maior necessidade da GI nessas instituições, com 50\%, é permitir não apenas responder a indagações mediante consulta, mas ajudar a especificar relatórios que contribuem no encaminhamento de soluções no setor; $32 \%$ - mudar a cultura corporativa e ajude a despertar/aumentar a consciência sobre a qualidade da informação e as demandas atuais da Sociedade da Informação. Só para a alternativa C (suportar decisões gerenciais no nível tático para realocação de recursos, correção do curso de ações, etc) não houve nenhum respondente.

Pode-se constatar aqui que as necessidades no que tange à GI são semelhantes, apresentando como maiores necessidades a obtenção e geração de informações que possam auxiliar na elaboração de relatórios e na solução de problemas do setor, e seja capaz de 
conscientizar sobre qualidade das informações, e mudar a cultura organizacional em relação à gestão da informação e sua relevância pessoal e coletiva.

Tendo em vista que as possíveis causas não foram investigadas, não é possível dizer o contexto em que tais problemas se configuraram, se foram resultados de um contexto organizacional improdutivo e outras influências ambientais, ou por conta de difíceis relacionamento entre a fonte e o receptor, por influência de características da informação e conhecimentos transferidos, conforme sugere Szulanski (1996), pelos fatores que dificultam o compartilhameto de conhecimento mencionados anteriormente por Mussi e Angeloni (2004), ou ainda por outros aspectos não tratados aqui. Entretanto, acreditamos que faz-se necessário que as informações organizacionais sejam compartilhadas, por meio de maior interação entre seus membros e seus departamentos.

Nas palavras de Alves e Barbosa (2010), o ato de compartilhar informação constitui-se como um tipo de interação social que permite a obtenção de organizações mais ágeis, inteligentes e mais flexíveis, e contribui para uma cultura da informação onde se valoriza processos mais participativos e menos individualistas. E acrescentam, as formas colaborativas de produção e utilização da informação tem em si forte potencial de novas formas organizativas de trabalho.

Em sexto lugar a questão proposta (representada pelo gráfico 4) está vinculada à associação da Gestão da Informação do setor com os objetivos da administração pública.

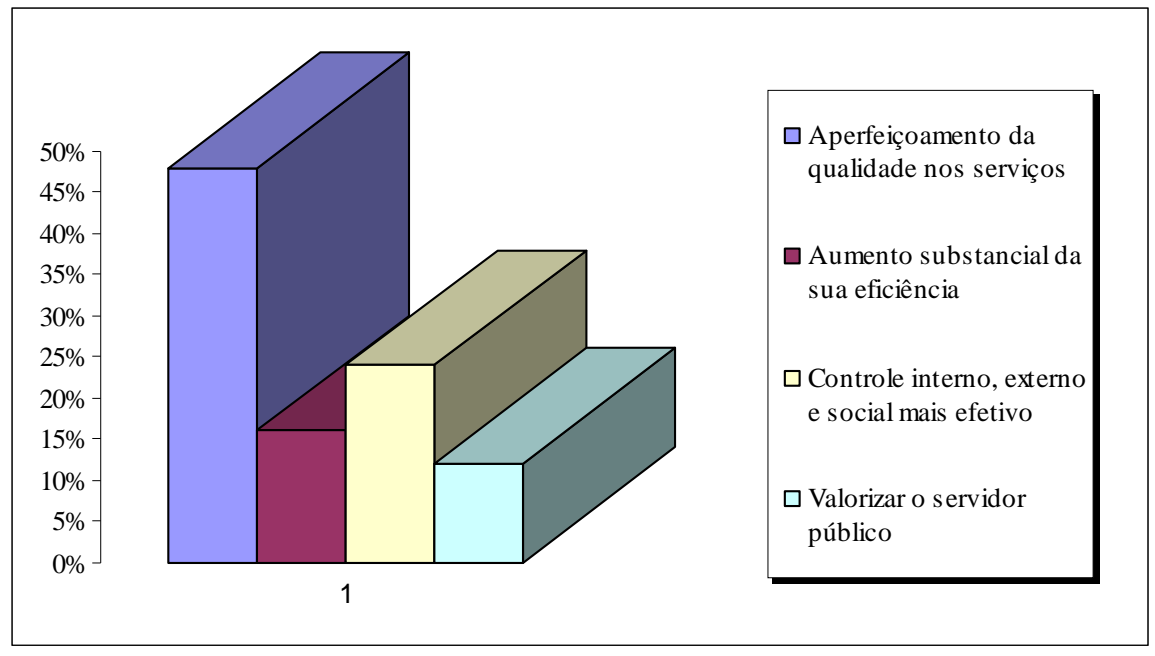

Gráfico 4: Associação da GI com objetivos da administração pública

Fonte: Dados da pesquisa

Como resultados $48 \%$ das respostas apontaram o aperfeiçoamento da qualidade da sua prestação de serviços à sociedade; $24 \%$ - buscar um controle interno, externo e social mais efetivo; $16 \%$ - aumentando substancialmente a sua eficiência, pois não há recursos infinitos disponíveis para o alcance de todas as demandas sociais e $12 \%$ - valorizar o servidor público. Ou seja, $72 \%$ das respostas voltam-se para o aperfeiçoamento da qualidade do serviço e busca de controles (interno, externo e social) mais efetivos. 
Motta (2007) enfatiza que a maior parte dos cidadãos experimenta um certo descaso e uma baixa qualidade na prestação de serviços, quando no contato com uma repartição pública. Talvez, esse seja um dos motivos pelas quais a preocupação com o aperfeiçoamento da qualidade dos serviços prestados tem se mostrado alta, conforme pode ser verificado no resultado acima apresentado. Um outro motivo pelo qual a associação da GI com os objetivos da administração pública está, na maior parte, voltada para uma busca de qualidade do serviço prestado e por controles mais efetivos, poderia estar relacionado ao fato de que, de modo geral, a administração pública e seus modelos de gestão vem sofrendo mudanças nas últimas décadas conforme apontam alguns estudos (ver ABRUCIO, 2007; MOTTA, 2007; SALM; MENEGASSO, 2009; por exemplos).

E por fim, o gráfico 5, referente à questão 7, mostra o panorama atual dos aspectos de projetos que contribuem para a modernização administrativa e GI com tecnologia.

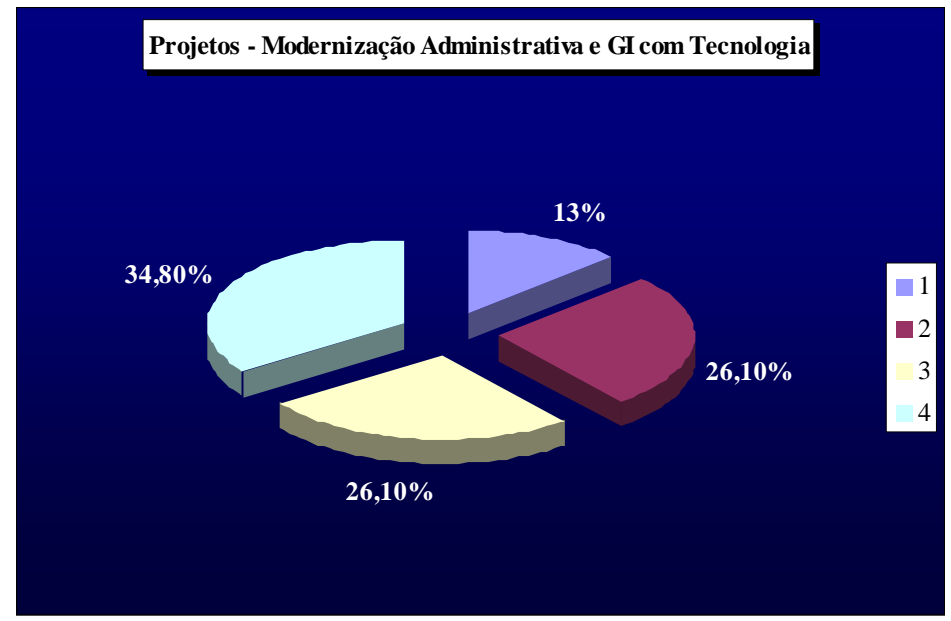

Gráfico 5 - Projetos para Modernização Administrativa e GI com Tecnologia Fonte: Dados da Pesquisa

\begin{tabular}{|c|l|}
\multicolumn{2}{l}{ Legenda } \\
\hline $\mathbf{1}$ & $\begin{array}{l}\text { Os projetos encontram-se especificados adequadamente e bem dimensionados para seu } \\
\text { funcionamento. }\end{array}$ \\
\hline $\mathbf{2}$ & A falta de recursos ainda não permitiu implementar tais projetos. \\
\hline $\mathbf{3}$ & A descontinuidade (de políticas e gestores) ainda não permitiu implementar tais projetos. \\
\hline $\mathbf{4}$ & $\begin{array}{l}\text { Não existem projetos, mas apenas diretrizes e iniciativas (empreendedorismo interno) na } \\
\text { direção da modernização administrativa e gestão da informação com tecnologia. }\end{array}$ \\
\hline
\end{tabular}

As alternativas que podem ser associadas aos projetos do setor para modernização administrativa e Gestão da Informação com tecnologia são: não existem projetos, mas apenas diretrizes e iniciativas (empreendedorismo interno) na direção da modernização administrativa e gestão da informação com tecnologia (34,8\%); a falta de recursos ainda não permitiu implementar tais projetos $(26,1 \%)$; e a descontinuidade (de políticas e gestores) ainda não permitiu a implementação desses projetos $(26,1 \%)$. 
Nesse caso, pode-se constatar que não há projetos para modernização administrativa e gestão da informação com tecnologia, e pode estar vinculado à falta de recursos para implementação daqueles projetos, e a não continuidade de gestão ou de políticas é um dos fatores que dificultam o desenvolvimento de projetos na área. Por fim, passamos às conclusões do estudo.

\section{CONCLUSÕES}

A tecnologia age como um catalisador para a implantação de um programa de Gestão do Conhecimento, entretanto, conforme Eric Tsui (2005), para se ter êxito, essa tecnologia precisa estar alinhada com uma estratégia definida e sustentada por um programa de mudança.

A atual a gestão da informação pública universitária possui primordialmente como função operacional a otimização do trabalho de rotina, e a oferta de maior qualidade nos serviços executados pelos seus colaboradores. As necessidades das instituições investigadas, em relação à Gestão da Informação, são similares. Como maiores necessidades estão a falta de informações que visam auxiliar na geração de relatórios e nas alternativas de soluções de problemas do setor, com o intuito de conscientizar sobre qualidade das informações, e, gradativamente alterar a cultura organizacional no que tange à gestão da informação e sua importância para o indivíduo e para o grupo.

Em relação às disparidades, em alguns momentos, entre as instituições pode-se inferir que as instituições públicas de ensino superior não possuem sistemas de informação iguais e padronizados. Isso pode ocorrer devido às diferenças em disponibilidade e distribuição de recursos; diferentes prioridades específicas de cada instituição e localidade; ausência de pessoas qualificadas para gerenciar o sistema de informação de modo adequado; entre outros fatores particulares de cada gestão e instituição. Apesar das diferenças que as instituições possuem uma infra-estrutura semelhante no que diz respeito ao sistema de informação setorial.

A falta de projetos para modernização administrativa e gestão da informação, pode ocorrer por alguns fatores, tais como a falta de recursos para implementação daqueles projetos; não continuidade de gestão ou de políticas (um dos fatores dificultadores do desenvolvimento de projetos); procedimentos extremamente burocráticos; resistência a qualquer tipo de mudança na cultura organizacional; bem como a ausência de uma política de gestão voltada para esse aspecto.

No que se refere ao gestor universitário, salienta-se que é necessário que o mesmo tenha uma visão estratégica, um bom relacionamento interpessoal e habilidade para negociar, competências também requeridas atualmente de gerentes em diversos tipos de organizações. Para tanto, a tecnologia e os sistemas de informação são ferramentas importantíssimas como apoio na execução e desempenho de suas funções. Os sistemas de informação nas palavras de Laudon e Laudon (2001), além de oferecer apoio, coordenação e controle para a tomada de decisão, visam ainda auxiliar os gerentes e seus colaboradores na resolução de problemas. 
Outras conclusões e resultados poderiam ser alcançados se o estudo fosse realizado sob outras perspectivas teóricas e metodológicas. Sugerimos, para ampliação da pesquisa e compreensão do tema abordado, a realização de estudos qualitativos, que possam, além de um aprofundamento sobre as questões já vistas neste trabalho, investigar também as causas.

\section{REFERENCIAS}

ABRUCIO, F. L. Trajetória recente da gestão pública brasileira: um balanço crítico e a renovação da agenda de reformas. Revista de Administração Pública - RAP, v. 41, Edição Especial Comemorativa, p. 67-86, 2007.

ALVES, A.; BARBOSA, R. R. Influências e barreiras ao compartilhamento da informação: uma perspectiva teórica. Ci. Inf., Brasília, DF, v. 39 n. 2, p.115-128, maio/ago., 2010.

ANGELONI, M. T. Elementos intervenientes na tomada de decisão. Revista Ciência da Informação. Brasília, v. 32, n. 1, p. 17-22, jan./abr. 2003.

BARROS, A. J. P. de \& LEHFELD, N. A. de S. Fundamentos de metodologia: um guia para iniciação científica. 2. ed. São Paulo: Pearson Makron Books, 2000.

BATISTA, F. F. Governo que aprende: gestão do conhecimento em organizações do executivo federal. Texto para Discussão n. 1022. Brasília: IPEA, jun. 2004.

BEAL, A. Gestão estratégica da informação: como transformar a informação e a tecnologia da informação em fatores de crescimento e de alto desempenho nas organizações. São Paulo: Atlas, 2004.

CARVALHO, I. C. L.; KANISKI, A. L. A sociedade do conhecimento e o acesso à informação: para que e para quem? Revista Ciência da Informação, Brasília, v. 29, n. 3, p. $33-39$, set/ dez 2000.

COLOSSI, N.; CONSENTINO, A.; QUEIROZ, E. G. de. Mudanças no contexto do ensino superior no Brasil: uma tendência ao ensino colaborativo. Revista FAE, Curitiba, v. 4, n.1, p.57-58, jan/abr 2001.

DAVENPORT, T.; PRUSAK, L. Conhecimento empresarial: como as organizações gerenciam o seu capital intelectual. Rio de Janeiro: Campus, 1998.

DAVENPORT, T.; MARCHAND, D. A.; DICKSON, T. Dominando a gestão da informação. Porto Alegre: Bookman, 2004.

DUFFY, Jan. Knowledge management and its influence on the records and information manager. Information Management Journal. v.35, n. 3, jul 2001.

LAUDON, K. C.; LAUDON, J. P. Sistemas de informação. 4 ed. Rio de Janeiro: LTC, 1999.

LAUDON, K. C.; LAUDON, J. P. Gerenciamento de sistemas de informação. 3 ed. Rio de Janeiro: LTC, 2001.

Luftman, J.; Papp, R.; Brier, T. Enablers and inhibitors of business-it alignment. Communications of the Association for Information Systems, v.1, n. 11, p. 4-15, 1999. 
MARRA, A. V. M.; MELO, M. C. de O. L. Docente-gerente: O Cotidiano de Chefes de Departamento e Coordenadores em uma Universidade Federal. In: ENCONTRO ANUAL DA ANPAD, 27, 2003, Atibaia. Anais... Atibaia: ANPAD, 2003. 1 CD-ROM.

MOTTA, P. R. A modernização da administração pública brasileira nos últimos 40 anos. Revista de Administração Pública - RAP, v. 41, Edição Especial Comemorativa, p. 87-96, 2007.

MUSSI, C. C.; ANGELONI, M.T. O compartilhamento do conhecimento no processo de implementação de sistemas de informação: um estudo de caso. FACEF Pesquisa, v. 7, n. 2, 2004.

NONAKA I.; TAKEUCHI H. Criação de conhecimento na empresa: como as empresas japonesas geram a dinâmica da inovação. Rio de Janeiro: Campus, 1997.

OLIVEIRA, L. C. de A.; CUNHA, M. A. V.C. SANTOS FILHO, H. P. dos. A tecnologia da informação na relação entre o Estado e o cidadão: a expectativa dos excluídos digitais num estudo de caso no Estado do Paraná. In: ENCONTRO ANUAL DA ANPAD, 27, 2003, Atibaia. Anais... Atibaia: ANPAD, 2003. 1 CD-ROM.

PEREIRA, C. M. L.; DORNELAS, J. S. Fatores promotores e inibidores do alinhamento estratégico da tecnologia da informação em uma situação de fusão: o caso de uma rede varejista. Revista de Administração Contemporânea - RAC, v. 14, n. 3, p. 495-515, Mai./Jun. 2010.

PERROTTI, E.; VASCONCELlOS, E. P. G. de. Estrutura Organizacional e Gestão do Conhecimento. In: ENCONTRO ANUAL DA ANPAD, 29, 2005, Atibaia. Anais... Atibaia: ANPAD, 2005. 1 CD-ROM.

REZENDE, D. A. Alinhamento do planejamento estratégico da tecnologia da informação ao planejamento empresarial: proposta de um modelo e verificação da prática em grandes empresas brasileiras. Tese de doutorado, UFSC - Universidade Federal de Santa Catarina, Florianópolis, SC, Brasil, 2002.

RICHARDSON, Roberto Jarry. Pesquisa social: métodos e técnicas. São Paulo: Atlas, 1999.

SALM, J. F.; MENEGASSO, M. E. Os pressupostos para implementação do novo serviço público e o capital social. In: XI Colóquio Internacional Sobre Poder Local, 2009, Salvador. Anais... Salvador, BA, 2009. 1 CD-ROM.

SELLTIZ, C.; JAHODA; DEUTSCH; COOK, S. W. Métodos de pesquisa nas relações sociais. São Paulo: EPU, 1975.

SPINELLI, Marcos Paulo. Implementação de projetos de modernização administrativa municipal suportados pela TI: estudo de casos em municípios do Estado de São Paulo. 164p.

Dissertação (Mestrado em Administração) - Faculdade de Economia, Administração e Contabilidade. USP, 2003.

SZULANSKI, G. Exploring internal stickiness: impediments to the transfer of best practice within the firm. Strategic Management Journal, v. 17, p. 27-43, 1996.

SVEIBY, K. E. A nova riqueza das organizações: gerenciando e avaliando patrimônios de conhecimento. Rio de Janeiro: Campus, 1998.

TERRA, J. C. C. BATISTA, F. F.; QUANDT, C. O.; PACHECO, F. F. Gestão do conhecimento na administração pública. Texto para discussão n. 1095. Brasília: IPEA, junho de 2005 . 
TRIVIÑOS, A. N. S. Introdução à pesquisa em ciências sociais: a pesquisa qualitativa em educação (o positivismo, a fenomenologia, o marxismo). São Paulo: Atlas, 1987.

TSUI, E. The role of IT in KM: where are we now and where are we heading? Journal of Knowledge Management, v. 9, n. 1, 2005.

TURBAN, E.; RAINER, R. K.; POTTER, R. E. Administração de tecnologia da informação: teoria e prática. Rio de Janeiro: Elsevier, 2005.

VASCONCELOS, F. de. Da Gestão do conhecimento à gestão da ignorância: uma visão coevolucionária. Revista de Administração de Empresas • Out./Dez. 2001 São Paulo, v. 41 n. 4 p. $98-102$. 